\title{
Medical Council of India's Amended Qualifications for Indian Medical Teachers: Well Intended, yet Half-hearted
}

\author{
Sunita VS Bandewar ${ }^{1}$, Amita Aggarwal ${ }^{2}$, Rajeev Kumar ${ }^{3}$, Rakesh Aggarwal $^{4}$, PeuSh Sahni $^{5}$ \\ AND SANJAY A PaI ${ }^{6}$ \\ ${ }^{1}$ Independent Senior Research Professional and Consultant in Global Health and Bioethics, Pune; Departments of ${ }^{2}$ Clinical \\ Immunology and ${ }^{4}$ Gastroenterology, SGPGI, Lucknow; Departments of ${ }^{3}$ Urology and ${ }^{5}$ GI Surgery, AIIMS, New Delhi; and \\ ${ }^{6}$ Department of Pathology, Columbia Asia Referral Hospital, Bengaluru; India. \\ Correspondence to: SunitaVS Bandewar (sunita.bandewar@utoronto.ca)and SanjayAPai, (sanjayapai@gmail.com)
}

Published online: December 29, 2017. PII:S097475591600106

$\Gamma$ he Medical Council of India (MCI) must be commended for its efforts to introduce definitive criteria for appointments and promotions for teachers in medical institutions. On June 8, 2017, the MCI issued a circular [1] to amend the Minimum Qualifications for Teachers in Medical Institutions Regulations, 1998 (henceforth Regulations, 1998) [2]. The amendment clarifies the minimum qualifications required for various postgraduate teaching positions in medical colleges. It indicates MCI's sustained engagement with qualifications of teachers in medical colleges, with the aim of enhancing the quality of teaching and thereby the quality of medical professionals passing out. However, we believe that these efforts continue to be inadequate in addressing the varied issues that face medical education and the educators in India.

Some of these issues are: $(i)$ the lack of transparency in the manner in which new medical colleges are approved, (ii) the variation in the proportion of private and public medical colleges across states, (iii) the lack of change and innovation in the undergraduate and postgraduate medical curricula to keep up with changing needs, $(i v)$ the poor uptake of newer teaching-learning methods, $(v)$ the poor quality of teachers in several medical colleges, (vi) methods used to assess teachers during selection and promotions, and (vii) failure to assess the impact of policy changes (such as a recent increase in the number of postgraduate seats) on the quality of medical education and training.

In this editorial, we focus on one of these issues, ie, the appointment and promotion of teachers in medical colleges. The MCI had on September 3, 2015 [3] stated its requirements with regard to research publications for eligibility for promotion of faculty members in medical colleges. This had been critiqued [4,5] mainly on four counts: exclusion of publications in 'electronic-only' journals from consideration for assessment of performance; awarding points only to original research articles or papers; awarding points only to first or second authors; and, the choice of indexing services for assessing the quality of a journal. While lauding the MCI's efforts towards improving the standards for teaching faculty at medical colleges in India, these critiques argued that an ill-informed framework for determining eligibility for promotion is likely be self-defeating and even harmful to the profession.

\section{A few steps forwards and a few steps backwards}

The 2017 Amendment [1] is noteworthy for it states that in order to be eligible for assessment, a paper must be published in "indexed" journals. This appears to be a step in the right direction because indexing indicates that a journal meets certain standards and quality within a specialty, specific to a particular index. However, in this amendment, the MCI has not specified any particular index(es). Thus, possibly the list of indexes previously specified in its 2015 order will continue to apply. Let us look at this issue more closely. Accepting only the MEDLINE-indexed journals would exclude some research in valuable allied fields, such as medical humanities, basic sciences and social sciences as applied

Note: This editorial is being published simultaneously in the Indian Internet Journal of Forensic Medicine and Toxicology, Indian Journal of Cancer, Indian Journal of Medical Ethics, Indian Journal of Physiology \& Pharmacology, Indian Journal of Rheumatology, Indian Journal of Urology, Indian Pediatrics, Journal of Anaesthesiology and Clinical Pharmacology and the National Medical Journal of India. It may also be published in forthcoming issues of other journals. 
to medicine. Thus, inclusion of other indexes may be useful for recognizing these diverse related disciplines beyond the pure health sciences, although with due diligence. For example, some indexes have little credibility as they are known to include pseudojournals (also known as 'predatory journals') in their listings. Hence, it is important that MCI specifies only those indexes which are reputed to have quality journals. The 2015 MCI list of eligible indexes has been faulted on this score [5]. Aggarwal and colleagues [5] had suggested the following list of acceptable databases: Medline, PubMed Central, Science Citation Index, Embase/Excerpta Medica, Scopus and IndMED. The latest amendment missed out on an opportunity to revise the list of eligible indexes.

The amendment does not specify whether or not papers published in "e-only" indexed journals are acceptable for assessment. Here too, possibly the stipulation in the 2015 order, that e-journals, are not included, will continue to apply. Currently, many e-only journals (e.g. PLoS group, BioMed Central, etc) are comparable in quality to, and at times even better than, those published as hard copy. Their inclusion would allow a much wider range of journals for the faculty to choose from for publishing their work.

Unfortunately, as with Regulations, 1998 [2], the 2017 Amendment [1] also limits the credit for authorship to only some of those listed on the author byline. Unlike the first version in which those listed as the first and the second authors were eligible, the amendment gives the credit for a paper to only the first author and the corresponding author. As critiqued earlier, this approach inhibits collaborative research and could be counterproductive by undermining the advancement of knowledge. Some of the best research today is multidisciplinary and multi-author.

\section{Problems untouched}

The MCI regulations, even after the recent amendment [1], are problematic in other aspects too. These lay down two criteria to assess a candidate's eligibility for a particular position: duration of service and number of research publications. One would expect the parameters assessed during appointment and promotion to be aligned with the responsibilities of teachers in medical colleges, with a strong convergence suggesting appropriateness and sufficiency of the criteria. In clinical or paraclinical departments, medical teachers have three primary activities; providing clinical or laboratory/imaging service, teaching, and doing research; which vary for different specialties However, in most medical colleges, irrespective of specialty, the research activity forms a small part of the total work of a medical teacher. Hence, any assessment of only research output without an assessment of the other two domains does not appear to be reasonable. What about the other two activities? Provision of clinical or laboratory services and teaching are integral to the core work of a medical faculty member. The assessment, if any, of these domains is only by the years of service put in. This appears unfair. The MCI regulations should address the issue of assessing medical faculty in all the three activity domains. Undue focus on research and not on the other two domains might prove to be detrimental both to the training of medical students as well as to clinical work.

Failure of the faculty to do research is a welldocumented problem in Indian medical colleges. It has been argued [6] that this is due to commercialization of medical education in the country. However, we believe that this phenomenon is multifactorial. One major reason may be a lack of interest and training to do research on part of the teachers, or of lack of infrastructure to facilitate research on part of the institutions. Also, good research requires financial resources - and most of the institutions, whether funded publicly- or privately have no or little funds dedicated to this activity. These factors may need to be corrected first, before we can expect research to be an important criterion for assessing eligibility for appointment and promotion of medical teachers.

Lack of adequate funding too discourages the MCI's approach. India has nearly 450 medical colleges. Let us assume that each college has around 100 teachers, and that each of the nearly 45,000 teachers needs to publish a research paper every three years. This translates to around 15,000 research papers a year. In addition, around 20,000 students join a medical postgraduate course every year in the country, and each of them has to write a thesis. Let us assume the "most optimum" case scenario - that each thesis results in a paper with a student and his teacher-guide as the two eligible authors. Even with this unlikely scenario, we would require to generate at least 20,000 new research ideas every year - a formidable task. For these research works to be novel and publishable, a large proportion of these ideas would need funding which is currently not available.

Another important consideration is whether there are sufficient peer-reviewed, "indexed" journals to publish this large body of work. The requirement to publish by teachers in Indian medical colleges and universities has seen a proliferation of "predatory journals" in India [79].We are not arguing that research may be altogether abolished as a criterion for eligibility and assessment of 
medical faculty. It is known that good research institutions globally and in India are sought after by students and patients alike, as these are considered better centres for learning and providing a better quality of care. However, whether the quality of teaching and patient care can necessarily be improved by mandating research of whatever quality remains uncertain.

Thus, it is not reasonable to make an assessment for promotion of a medical teacher solely on the basis of research activity - that too by counting the number of publications.

\section{The way forward}

It is evident from the above that the assessment of medical teachers must encompass all the three domains of their activities. Furthermore, the assessment should focus not on quantity, as is done currently by counting only years of service or number of papers, but on the quality of work in each sphere. Unfortunately, we will be told that "assessment of quality" would not be objective, and would be liable to bias and manipulation. However, this is an excuse for not doing what seems to us the right thing to do. Around the world, as in many fields in our country, employees are assessed using the so-called "subjective" criteria, with sufficient reliability. Setting up such systems - though admittedly hard - is not impossible. These will surely take time, effort and commitment to set up. But if we unquestioningly accept the simplistic tools such as publication count, we will never move to a higher plane. Hence, as a profession, we need to initiate debate for moving towards better systems of assessing quality. Such an assessment system would necessarily mean a multi-pronged evaluation - by peers, students as well as administrators.

Variation is an important rule of nature and all medical teachers cannot be expected to have exactly the same skill set. Thus, one of them may be an excellent researcher, but not a particularly good teacher. Similarly, someone else might be better at providing a laboratory service than doing research. This is in fact desirable since it allows some persons to excel in one specific area beyond the average skill level expected, and should be encouraged. This requires that individuals with different skill sets and inclinations be provided the opportunity to do more of what they are good at and less of what they may not be so skilled at. The proportion of time spent on the three core activities referred to above could thus vary between different teachers. Thus, it would be reasonable that the assessment of medical teachers for the quality of work would be a weighted average of the quality of work in the three domains, with the weights decided by the predefined proportion of time spent by each teacher on activities in these domains. Clearly defining each faculty member's job description at the time of appointment or during the course of service will facilitate and/or enable such an approach to assessment.

Each core activity could be assessed using different parameters. Teaching should be assessed by the end user; $i e$, the student and the performance of students in an assessment should be part of the assessment of a teacher. Similarly, peers should sit in on teaching activities and provide a peer evaluation. These suggestions are neither exhaustive nor necessarily tested to be appropriate for our milieu. Hence, a constant evaluation and evolution of these methods would be essential.

Research should be evaluated but not by the number of publications. The quality of a medical faculty's research output should be assessed. This would include a peer evaluation of the individual's select few publications - a smaller number at the time of selection and an increasing number with each step in the academic ladder. For example, two best papers at the time of initial selection as a faculty member, five best at the next level, and seven and ten in the further steps. As almost all medical faculty positions in India are tenured, there are few who would make the effort to write a grant application and obtain funding. Those who do so should be assessed on the quality of their grant applications or the amount of funding obtained.

How does one assess the service component of the medical faculty? This could be difficult to do but an effort should be made to use laboratory and clinical audits, and peer and patient assessment and feedback.

All this must be done transparently. The assessors, the method and process of assessment and the final evaluation must all be transparent. Anybody can make errors and hence there must be a transparent system of appeals and evaluations of appeals. Questioning a decision with sound reasoning must be permitted but the process must be free of corruption.

We are aware that some of these suggestions may appear radical in the current Indian scenario. We believe that the Indian medical education system is in urgent need of radical corrective steps, if we are to prevent it from continuing on the slippery slope that it presently is on. Minor tinkering, such as the MCI seems to be engaged in, will not do.

\section{REFERENCES}

1. Medical Council of India. Amendment Notification. New Delhi: 2017 June 5. Available from: http://www.mciindia. org/Rules-and-Regulation/Gazette\%20Notifications\% 20-\%20Amendments/TEQ-08.06.2017.pdf. Accessed June 
$13,2017$.

2. Medical Council of India. Minimum Qualifications for Teachers in Medical Institutions Regulations, 1998 (Amended upto 8th June, 2017). Available from: http:// www.mciindia.org/Rules-and-Regulation/TeachersEligibility-Qualifications-Rgulations-1998.pdf. Accessed June 13, 2017.

3. Medical Council of India. 2015. Clarification with Regard to Research Publications in the Matter of Promotion for Teaching Faculty in Medical Colleges/Institutions. Document No. MCI-12(1)/2015-TEQ/131880.

4. Bandewar SVS, Pai SA. Regressive trend: MCI's approach to assessment of medical teachers' performance. Indian J Med Ethics. 2015;12:192-5.

5. Aggarwal R, Gogtay N, Kumar R, Sahni P, for the Indian Association of Medical Journal Editors. The revised guidelines of the Medical Council of India for academic promotions: need for a rethink. Indian J Med Ethics. 2016;1:2-5.

6. Ray S, Shah I, Nundy S. The research output from Indian medical institutions between 2005 and 2014. Curr Med Res Pract. 2016;6:49-58.
7. Moher D, Shamseer L, Cobey KD, Lalu MM, Galipeau J, Avey MT, et al. Stop this waste of people, animals and money. Nature. 2017;549:23-5.

8. Prasad R. Fake journals: 'Make in India' gone wrong. Available from: http://www.thehindu.com/sci-tech/fakejournals-make-in-india-gone-wrong/article7800231.ece. Accessed December 5, 2017.

9. Seethapathy GS, Santhosh Kumar JU, Hareesha AS. India's scientific publication in predatory journals: Need for regulating quality of Indian science and education. Curr Sci. 2016;111:1759-64.

Note: This editorial is being published simultaneously in the Indian Internet Journal of Forensic Medicine and Toxicology, Indian Journal of Cancer, Indian Journal of Medical Ethics, Indian Journal of Physiology \& Pharmacology, Indian Journal of Rheumatology, Indian Journal of Urology, Indian Pediatrics, Journal of Anaesthesiology and Clinical Pharmacology, and the National Medical Journal of India. It may also be published in forthcoming issues of other journals.

\section{ADDITIONAL REVIEWERS FOR 2017}

\section{INDIAN PEDIATRICS}

\section{Volume 54, November - December, 2017}

The present status of this Journal is largely dependent on the expertise and selfless cooperation of the following Reviewers whose help we gratefully acknowledge. We are indebted to them for this service.

_ Journal Committee

\begin{tabular}{|c|c|c|}
\hline Afzal K & Dutta D & Mohanty S \\
\hline Agarwal A & Dwivedi P & Mortada El-S \\
\hline Aggarwal KCC & & Moxon S \\
\hline Aradhya AS & Faridi MMA & \\
\hline Bavare A & Ganguly N & Nagesh K \\
\hline Bhat SR & Garekar S & Paul AK \\
\hline Bhat RY & Godbole S & Prashanth GP \\
\hline Bhatt GC & Gowrishankar N & \\
\hline Bhatia P & Gupta G & Rao SV \\
\hline Bisht SS & Gupta NK & \\
\hline & Gupte MD & Sankar MJ \\
\hline Chandrasekaran A & Guruprasad G & Sharma A \\
\hline Chaudhary N & Grover P & Shashidhar A \\
\hline Chawla M & Haroon NN & $\begin{array}{l}\text { Somashekar AR } \\
\text { Squires J }\end{array}$ \\
\hline Dadhich JP & Jain $\mathrm{N}$ & Subramani S \\
\hline Dalwai SH & $\operatorname{Jain} N$ & Surana V \\
\hline Das $\mathrm{S}$ & Khadgawat R & \\
\hline Dhingra D & & Thakare MM \\
\hline Dhirar N & Mathew J & Thayyil S \\
\hline Dhull R & Mishra K & \\
\hline Dutta AK & Mohan N & Vaid S \\
\hline
\end{tabular}




\title{
Assisted Physical Exercise for Preterm Neonates
}

\author{
*Swathi Chacham and Rachna Pasi \\ Department of Pediatrics, All India Institute of Medical Sciences, Rishikesh, Uttarakhand, India. \\ *swathi.m.lahiri@gmail.com
}

$\mathrm{M}$ etabolic bone disease (MBD) of prematurity, also known as osteopenia/ rickets of prematurity, is a major comorbidity in preterm, very low birth weight (VLBW) and chronically ill infants leading to deformities and even spontaneous fractures, if left untreated [1-3]. It is defined as reduced bone mineralization when compared to predicted level of bone mineral content of a fetus or neonate of similar gestational age or size along with biochemical markers and/or radiological findings [1]. The reported incidence varies from $16 \%$ in VLBW to $40 \%$ in extremely low birth weight (ELBW) neonates [2,3]. The key etiological factors remain inadequate calcium and phosphorous stores in the face of accelerated skeletal growth. Also, use of medications (steroids, caffeine), prolonged parenteral nutrition and immobilization in premature infants has shown to aggravate MBD [4,5]. MBD characteristically presents within 6-16 weeks after birth. Increased physical activity in preterm infants has shown to enhance bone mineralization along with better weight gain $[4,6]$.

As the disease advances, biochemical abnormalities tend to increase significantly. These include hypocalcemia, hypophosphatemia, hyperphosphatasia and secondary hyperparathyroidism. Moreover, urinary phosphate wasting can ensue in these preterm neonates and vitamin D deficiency can also compound these effects [1-3]. On the other hand, biochemical derangements may or may not be associated with rachitic changes. Interestingly, MBD can also remain unidentified radiologically, as it needs profound loss of bone mineralization $(>40 \%)$ to manifest characteristic radiological features. Some studies have evaluated bone mineral density, bone mineral content and whole-body lean mass in preterm neonates using bone densitometry by dual-energy $X$-ray absorptiometry (DXA) $[1,4]$.

Newer studies propose that estimating bone Speed of sound (SOS) by quantitative ultrasound could predict bone turnover in preterm infants alongside standard biochemical markers [7-9]. Measuring bone SOS over mid-tibial shaft is a non-invasive tool that can indirectly depict bone strength. This was found to be higher in term neonates (median $3079 \mathrm{~m} / \mathrm{s}$ ) when compared to premature neonates (median $2911 \mathrm{~m} / \mathrm{s}$ ), in a study by McDevitt, et al. [7]. Many studies report good correlation between bone SOS and gestational age [7-11]. It was also seen that bone SOS was less in premature neonates who reached corrected age of full term neonates when compared to term neonates [8].

Majority of the preventive strategies for MBD target nutritional enhancement. However, the novel approach would be to focus on improving physical activity in these tiny neonates along with optimum nutritional supplementation, which might enhance bone metabolism and mineralization. Assisted physical exercise using passive range of motion of the extremities has shown to significantly increase the body weight, bone mineralization and osteogenesis. Some studies have shown that the exercise could attenuate the postnatal reduction in bone SOS $[10,11]$.

The study by Shaw, et al. [12] in this issue of Indian Pediatrics is an open label randomized controlled trial, conducted in a level-3 neonatal unit from a tertiary care teaching hospital in Northern India. This is the first published study from India that evaluates the role of assisted physical exercise for enhancing bone strength in preterm infants as measured by quantitative ultrasound. This study has addressed two newer methods in predicting and preventing MBD in preterm neonates. First, they have used latest non-invasive methodology of estimating bone strength by measuring SOS in tibia, by quantitative ultrasound along with other metabolic work-up. Second, the authors evaluated the role of assisted physical exercise that aims to combat immobilization, one of the determinants of MBD. This collectively strengthens the study coupled with its high quality study design and methodology executed. The authors assessed the impact of daily assisted physical exercise conducted by mothers in stable preterm infants born at 27 to 34 weeks of gestation, from one week of postnatal age to term gestation on bone 
strength as estimated by tibial bone SOS at 40 weeks post menstrual age (PMA). The sample size was larger than previous randomized controlled trials $[11,12]$. The present study also included intrauterine growth restricted neonates when compared to the study by Litmanovitz, et al. [11], which comprised only appropriate for age neonates. This is much needed in Indian perspective when compared to western countries, as a sizable proportion of Indian neonates have intrauterine growth restriction. Captivatingly, the study had an exceptional follow up rate of $94 \%$, which is difficult to achieve otherwise, and which was much higher than previous studies and the follow-up period was longer. Neonates in the exercise group received physical exercise and mothers were trained very meticulously, which also included video demonstration and mothers were provided with the videos containing standardized method, and the method was reassessed by the authors in periodic follow-up visits. Likewise, the authors have evaluated the primary outcome, SOS in left tibia with utmost precision.

Schulzke, et al. [4] concluded from their Cochrane review of eleven small randomized trials of moderate methodological and reporting quality that physical activity programs might lead to moderate bone mineralization and short-term growth in preterm neonates. As the effect size was small and the baseline risk of decreased bone mineralization and growth was low in their review, the clinical relevance of their results is unclear.

This study would make a path for further larger trials comparing the role of assisted physical exercise by mother in preterm neonates and its influence on their bone strength. Also, the results of this study would provide baseline data of tibial SOS by quantitative ultrasound for Indian neonates.

Funding: None; Competing interests: None stated.

\section{REFERENCES}

1. Rustico SE, Calabria AC, Garber SJ. Metabolic bone disease of prematurity. J Clin Transl Endocrinol. 2014;1:85-91.

2. Backstrom MC, Kuusela AL, Maki R. Metabolic bone disease of prematurity. Ann Med. 1996;28:275-82.

3. Takada M, Shimada M, Hosono S, Tauchi M, Minato M, Takahashi $\mathrm{S}$, et al. Trace elements and mineral requirements for very low birth weight infants in rickets of prematurity. Early Hum Dev. 1992;29:333-8.

4. Schulzke SM, Kaempfen S, Trachsel D, Patole SK. Physical activity programs for promoting bone mineralization and growth in preterm infants. Cochrane Database Syst Rev. 2014;4:CD005387.

5. Steichen J, Gratton TL, Tsang RC. Osteopenia of prematurity: The cause and possible treatment. J Pediatr. 1980;96:528-34.

6. Field T, Diego M, Hernandez-Reif M. Preterm infant massage therapy research: A review. Infant Behav Dev. 2010;33:115-24.

7. McDevitt H, Tomlinson C, White MP, Ahmed SF. Quantitative ultrasound assessment of bone in preterm and term neonates. Arch Dis Child Fetal Neonatal Ed. 2005;90:F341-42.

8. Nemet D, Dolfin T, Wolach B, Eliakim A. Quantitative ultrasound measurements of bone speed of sound in premature infants. Eur J Pediatr. 2001;160:736-40.

9. Rubinacci A, Moro GE, Boehm G, De Terlizzi F, Moro GL, Cadossi R. Quantitative ultrasound for the assessment of osteopenia in preterm infants. Eur J Endocrinol. 2003;149:307-15.

10. Eliakim A, Litmanovitz I, Nemet D. The role of exercise in prevention and treatment of osteopenia of prematurity: An Update. Pediatr Exerc Sci. 2017;29:450-5.

11. Litmanovitz I, Dolfin T, Arnon S, Regev RH, Nemet D, Eliakim A. Assisted exercise and bone strength in preterm infants. Calcif Tissue Int. 2007;80:39-43.

12. Shaw SC, Sankar MJ, Thukral A, Natarajan CK, Deorari $\mathrm{AK}$, Paul VK, et al. Assisted physical exercise for improving bone strength in preterm infants less than 35 weeks gestation: A randomized controlled trial. Indian Pediatr. 2018;55:115-20.

13. Chen HL, Lee CL, Tseng HI, Yang SN, Yang RC, Jao HC. Assisted exercise improves bone strength in very low birth weight infants by bone quantitative ultrasound. J Pediatr Child Health. 2010;46:653-9. 


\title{
Prevention of Neurocognitive Impairment in Children Through Newborn Screening for Congenital Hypothyroidism
}

\author{
PSN MENON \\ Department of Pediatrics, Jaber Al-Ahmed Armed Forces Hospital, Kuwait \\ psnmenon@hotmail.com
}

$\mathrm{C}$ ongenital hypothyroidism $(\mathrm{CH})$ is probably the most important preventable cause of intellectual disability in children [1]. $\mathrm{CH}$ has been reported in approximately 1 in 1000 to 4000 births from various parts of the world [2]. Some developing countries, including Iran and India, have reported a higher incidence of $\mathrm{CH}[3,4]$.

Most newborn screening (NBS) programs use serum thyroid-stimulating hormone (TSH) as a primary test, and positive tests are confirmed by serum thyroxine (T4) levels. Infants with confirmed $\mathrm{CH}$ are started on treatment with levothyroxine (LT4) to achieve euthyroid state to prevent neurocognitive disabilities. TSH peaks in the first few days after birth and falls rapidly to 4-fold lower levels over the next few days. Mild increases in TSH over the recommended cut-off in NBS protocols for $\mathrm{CH}$ are often misclassified as normal. A significant number of these newborns may develop permanent primary hypothyroidism on follow-up. For this reason, many NBS programs order a second specimen in situations where the TSH concentration is mildly elevated between the cut-off and an upper limit of 40 or $50 \mathrm{mU} / \mathrm{L}[5,6]$. A recent study noted that even in USA, many programs do not adjust TSH cut-offs according to the infant's age, and initial as well as repeat TSH measurements are performed outside the age for which the cut-offs were established [7].

NBS and early LT4 therapy have markedly reduced the prevalence of intellectual disability in children with $\mathrm{CH}$ from $8-28 \%$ to $1 \%$ or less [8]. Mild neurocognitive impairment is reported despite diagnosis and treatment of $\mathrm{CH}$ following NBS. These include reduced intelligence quotient (IQ), behavioral problems, attention deficits and subtle motor, language and visuospatial impairments [5,9-12]. These are attributed to negligible T4 availability before birth and postnatal factors, including delayed diagnosis, delayed initiation of treatment [13], later time to normalize thyroid function [14], both under and overtreatment with LT4 [9,15], and fewer follow-up clinic visits [16]. Parental education and problems in communicating with parents in rural settings are other important barriers.
The severity of $\mathrm{CH}$, as defined by the levels of $\mathrm{T} 4$ and $\mathrm{TSH}$ at the time of diagnosis, is one of the most important risk factors for neurocognitive development in children with $\mathrm{CH}[10,11]$. Intellectual impairment is more common with thyroid agenesis than other etiologies [13]. A role for prenatal hypothyroidism remains unconfirmed. The maternal $\mathrm{T} 4$ transferred by the placenta has a protective effect on the fetus, but cord T4 levels in newborns with $\mathrm{CH}$ are lower than normal controls [17]. The study by Rahmani, et al. [3], published in this issue of Indian Pediatrics, noted that the children with permanent $\mathrm{CH}$ have greater deficit in IQ compared to the children with transient $\mathrm{CH}$, despite early detection and treatment unlike previous studies, which failed to note any such association [18].

It is possible to achieve a better outcome with earlier treatment and an initial high-dose of LT4, which rapidly normalizes thyroid function [19]. The European Society for Pediatric Endocrinology (ESPE) consensus guide-lines recommend that an initial LT4 dose of 10-15 $\mu \mathrm{g} / \mathrm{kg}$ per day should be given as soon as possible and no later than 2 weeks after birth [6]. High-dose LT4 treatment may increase the free $\mathrm{T} 4$ levels to supraphysiologic levels with resultant temperament, attention, behavior and psychiatric problems later.

Better outcomes may be achieved with more frequent follow-up visits and testing than those recommended currently [20]. ESPE guidelines recommend that the first follow-up examination should take place 1-2 weeks after the start of LT4 treatment. Subsequent evaluation should take place every 2 weeks until a complete normalization of TSH concentration is reached; then every 1 to 3 months thereafter until the age of 12 months. Between the ages of 1 and 3 years, children should undergo frequent clinical and laboratory evaluations (every 2 to 4 months). Thereafter, evaluations should be carried out every 3 to 12 months until growth is completed [6]. Simple tools such as the Denver Developmental Screening Test (DDST) can be effectively used for neurodevelopmental screening at a younger age in children with CH on LT4 therapy [21].

We lag behind in our programs for NBS. NBS 
programs in India are currently limited to a few states and union territories. The reported incidence of $\mathrm{CH}$ by NBS in India ranges from 1 in 1000 to 3100 [4]. Undiagnosed for months and years, many children with $\mathrm{CH}$ are being brought for evaluation with significant neurocognitive morbidity at a later age. The Indian Society for Pediatric and Adolescent Endocrinology had recently come out with locally relevant and cost-effective strategies for implementing NBS for CH (ISPAE, personal communication). This emphasizes the need for establishing NBS programs in all states of India. To achieve a better neurodevelopmental outcome, our NBS procedures should ensure that samples are collected and transported in time, age-specific cut-offs for TSH and T4 are defined, and results communicated to parents in time so that the affected newborns are brought to the treating team to confirm the diagnosis and start LT4 therapy within the first two weeks after birth. It is important to strengthen the surveillance system to ensure timely visits to the physician and efficient control of serum thyroid hormones levels to assure euthyroid state in children with $\mathrm{CH}$. We have a long way to go!

Funding: None; Competing interest: None stated.

\section{REFERENCES}

1. Schoenmakers N, Alatzoglou KS, Chatterjee VK, Dattani MT. Recent advances in central congenital hypothyroidism. J Endocrinol. 2015;227:R51-71.

2. Deladoey J, Ruel J, Giguere Y, van Vliet G. Is the incidence of congenital hypothyroidism really increasing? A 20-year retrospective population-based study in Quebec. J Clin Endocrinol Metab. 2011;96:2422-9.

3. Rahmani K, Yarahmadi S, Etemad K, Mehrabi Y, Aghang $\mathrm{N}$, Khoosha A, et al. Intelligent quotient at the age of 6 years of Iranian children with congenital hypothyroidism. Indian Pediatr. 2018; 55:121-4.

4. Gopalakrishnan V, Joshi K, Phadke SR, Dabadghao P, Agarwal M, Das V, et al. Newborn screening for congenital hypothyroidism, galactosemia and biotinidase deficiency in Uttar Pradesh, India. Indian Pediatr. 2014;51:701-5.

5. Albert BB, Heather N, Derraik JG, Cutfield WS, Wouldes $\mathrm{T}$, Tregurtha $\mathrm{S}$, et al. Neurodevelopmental and body composition outcomes in children with congenital hypothyroidism treated with high-dose initial replacement and close monitoring. J Clin Endocrinol Metab. 2013; 98:3663-70.

6. Leger J, Olivieri A, Donaldson M, Torresani T, Krude H, van Vliet G, et al. European Society for Paediatric Endocrinology consensus guidelines on screening, diagnosis, and management of congenital hypothyroidism. Horm Res Paediatr. 2014;81:80-103.

7. Kilberg MJ, Rasooly IR, LaFranchi SH, Bauer AJ, Hawkes CP. Newborn screening in the US may miss mild persistent hypothyroidism. J Pediatr. 2018;192:204-8.

8. Grosse SD, van Vliet G. Prevention of intellectual disability through screening for congenital hypo-thyroidism: how much and at what level? Arch Dis Child. 2011;96:374-9.

9. Oerbeck B, Sundet K, Kase BF, Heyerdahl S. Congenital hypothyroidism: influence of disease severity and Lthyroxine treatment on intellectual, motor, and schoolassociated outcomes in young adults. Pediatrics. 2003;112:923-30.

10. Kempers MJ, van der Sluijs Veer L, Nijhuis-van der Sanden RWG, Lanting CI, Kooistra L, Wiedijk BM, et al. Neonatal screening for congenital hypothyroidism in The Netherlands: cognitive and motor outcome at 10 years of age. J Clin Endocrinol Metab. 2007;92:919-24.

11. Dimitropoulos A, Molinari L, Etter K, Torresani T, LangMuritano M, Jenni OG, et al. Children with congenital hypothyroidism: long-term intellectual outcome after early high-dose treatment. Pediatr Res. 2009;65:242-8.

12. Rovet JF. Children with congenital hypothyroidism and their siblings: do they really differ? Pediatrics. 2005; 115:e52-7.

13. Bongers-Schokking JJ, Koot HM, Wiersma D, Verkerk PH, de Muinck Keizer-Schrama SMPF. Influence of timing and dose of thyroid hormone replacement on development in infants with congenital hypothyroidism. J Pediatr. 2000;136:292-7.

14. Hauri-Hohl A, Dusoczky N, Dimitropoulos A, Leuchter RH, Molinari L, Caflisch J, et al. Impaired neuromotor outcome in school-age children with congenital hypothyroidism receiving early high-dose substitution treatment. Pediatr Res. 2011;70:614-8.

15. Salerno M, Militerni R, Bravaccio C, Micillo M, Capalbo D, Di MS, et al. Effect of different starting doses of levothyroxine on growth and intellectual outcome at four years of age in congenital hypothyroidism. Thyroid. 2002;12:45-52.

16. Kreisner E, Schermann L, Camargo-Neto E, Gross JL. Predictors of intellectual outcome in a cohort of Brazilian children with congenital hypothyroidism. Clin Endocrinol (Oxf). 2004;60:250-5.

17. Derksen-Lubsen G, Verkerk P. Neuropsychologic development in early treated congenital hypothyroidism: Analysis of literature data. Pediatr Res. 1996;39:561-6.

18. Hollanders JJ, Israels J, van der Pal SM, Verkerk PH, Rotteveel J, Finken MJ. No association between transient hypothyroxinemia of prematurity and neurodevelopmental outcome in young adulthood. J Clin Endocrinol Metab. 2015;100:4648-53.

19. Jones JH, Gellen B, Paterson WF, Beaton S, Donaldson MDC. Effect of high versus low initial doses of L-thyroxine for congenital hypothyroidism on thyroid function and somatic growth. Arch Dis Child. 2008;93:940-4.

20. Mathai S, Cutfield WS, Gunn AJ, Webster D, Jefferies C, Robinson E, et al. A novel therapeutic paradigm to treat congenital hypothyroidism. Clin Endocrinol (Oxf). 2008;69:142-7.

21. Bulus AD, Tiftik E. Evaluation of neurodevelopment of children with congenital hypothyroidism by the Denver Developmental Screening Test. J Pediatr Endocrinol Metab. 2017;30:1061-6. 